\title{
Purification of Biodiesel Using Activated Carbon Produced from Cocoa Pod Husk
}

\author{
Devita Rachmat ${ }^{l}$, Aprillia D. Agustin ${ }^{l}$, and Doty D. Risanti ${ }^{l}$ \\ ${ }^{1}$ Department Engineering Physics, Institut Teknologi Sepuluh Nopember, Surabaya, Indonesia
}

\begin{abstract}
The purity level of waste cooking oil that use as raw material for biodiesel production has a strong influence on its fuel properties. In this study, activated carbon from cocoa pod husk activated with was used for purification in pre-treatment process of biodiesel production. The result showed that the activated carbon can decrease the water content and FFA and produce well-characterized biodiesel correspond to the Indonesian National Standard requirement.
\end{abstract}

\section{Introduction}

Biofuel has recently attracted huge attention in many countries because of its renewability, better gas emissions, and its biodegradability. Biodiesel is superior to conventional diesel in terms of its sulfur content, aromatic content and flash point. It is essentially sulfur free and non-aromatic while conventional diesel can contain up to $500 \mathrm{ppm} \mathrm{SO}_{2}$ and $20-40 \%$ aromatic compounds and becomes one solution in reducing atmospheric pollution.

According to Utlu and Kocak [1], there was on average of a decrease of $14 \%$ for $\mathrm{CO}_{2}, 17.1 \%$ for $\mathrm{CO}$ and $22.5 \%$ for smoke density when using biodiesel.

Biodiesel can be produced from vegetable oils, however, the total manufacturing cost is unfavorable since the price could be 1.5 to 2 times higher than that for diesel [2]. On the other hand, the price of waste cooking oils (WCO) is 2-3 times cheaper than virgin vegetable oils which make WCO more attractive. The improper handling of unprocessed WCO promotes poor environmental impact due to its harmful disposal of these waste oils, such ends up in streams of the drains or leaches groundwater. It is known that the purity level of biodiesel from WCO has a strong influence on its fuel properties. Generally, biodiesel from WCO contains a large amount of water and a high proportion of free fatty acid (FFA). Thus, a pretreatment of WCO is needed to avoid saponification which leads to product separation and low fatty acid methyl ester (FAME). According to [3], pretreatment was successfully undertaken by using activated carbon and resulted in a lower water content and FFA.
There has been an increasing interest in the production of activated carbon from agricultural by-products and industrial waste. Cocoa pod husk [4-6] and different agricultural and forest wastes as raw materials, e.g. macadamia nutshell [7], rice husk [8-10], jatropha husk [11], wood apple shell [12], pine nutshell [13], oil palm shell [14], seed shell of the palm tree [15], sago waste [16], guava seed [17], almond shell, pistachio shell, walnut shell [18], olive mill waste [19] and others have been used in the production of activated carbon thereby adding value to these agricultural wastes and thus recycling them. This research focuses on the use of activated carbon prepared from cocoa pod husk using $\mathrm{HCl}$ as activating agents with a view to preparing, characterizing and investigating the adsorption effectiveness of the charcoal in the pretreatment of WCO.

\section{Methods}

Cacao pod wastes were dried in an oven at $100^{\circ} \mathrm{C}$ for 24 hours to remove the water content. They were subsequently crushed into powder and sieved using 60 mesh siever. The powder was then heated at 3 temperatures ranging from $250^{\circ} \mathrm{C}$ to $350^{\circ} \mathrm{C}$ for 2 hours. 37.5 gram of the powder was then mixed with $75 \mathrm{ml}$ of $\mathrm{HCl} 2 \mathrm{M}$, stirred for 4 hours at $80^{\circ} \mathrm{C}$ and kept at room temperature for 24 hours. The activated charcoal was subsequently heated again at $200^{\circ} \mathrm{C}$ for 3 hours. For phase present, surface area and functional groups of the activated charcoal were determined through XRD, FTIR spectroscopy, and SEM, respectively

The collected $\mathrm{WCO}$ was heated at $120^{\circ} \mathrm{C}$ for at least 5 minutes to remove the water content. After that, the activated charcoal was immersed in WCO for 10 hours 
and filtered to remove any solid impurities. The final product was then reheated at $120^{\circ} \mathrm{C}$ for 2 minutes.

Lye solution was made from a mixture of $156.25 \mathrm{ml}$ methanol and 3.75 gram $\mathrm{KOH}$ under vigorous stirring for 5 minutes. For transesterification, the filtered $\mathrm{WCO}$ was reheated again at $120^{\circ} \mathrm{C}$ for 5 minutes and the temperature was gradually dropped to $55^{\circ} \mathrm{C}$. Under stirring, $25 \mathrm{ml}$ lye solution was added dropwise to the WCO for 1 hour. The result was kept for 8 hours until two layers were obtained, the upper was the methyl esters and the lower was the glycerol. Glycerol layer was discarded and the methyl ester layer was subsequently washed by using water and kept for 4 hours. The final solution was prefiltered again using whatman paper.

Properties of the purified biodiesel were measured according to the ASTM standards, i.e. ASTM D1298 for density, ASTM D445 for kinematic viscosity, ASTM D93-80 for flash point, ASTM D2500 for cloud point and ASTM D97 for pour point.

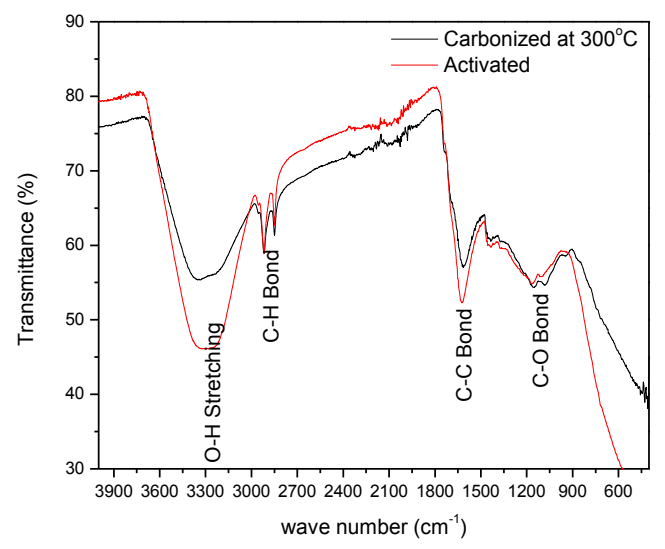

Fig. 1. FTIR Spectra for Carbonized and HCl-Treated Cacao Pod Husk.

Table 1. Elements Content in Activated Carbon.

\begin{tabular}{|l|l|l|l|l|}
\hline Element & $C$ & $O$ & $C l$ & $K$ \\
\hline Atomic \% (at. \%) & 74.65 & 24.75 & 0.48 & 0.12 \\
\hline
\end{tabular}

\section{Results and discussions}

\subsection{Structure of Cacao Pod after carbonization}

According to thermogravimetry results [20] the obtained weight losses during carbonization were $10.27 \%, 13.56 \%$ and $17.64 \%$ at temperatures of 250,300 and $400^{\circ} \mathrm{C}$, respectively. The strong decrease in weight at $400^{\circ} \mathrm{C}$ corresponds to the decomposition of lignocellulose whereas at $250^{\circ} \mathrm{C}$ is attributed to the decomposition of hemicellulose [22]. Thermal degradation has taken place through heat supplied during the carbonization process [5].

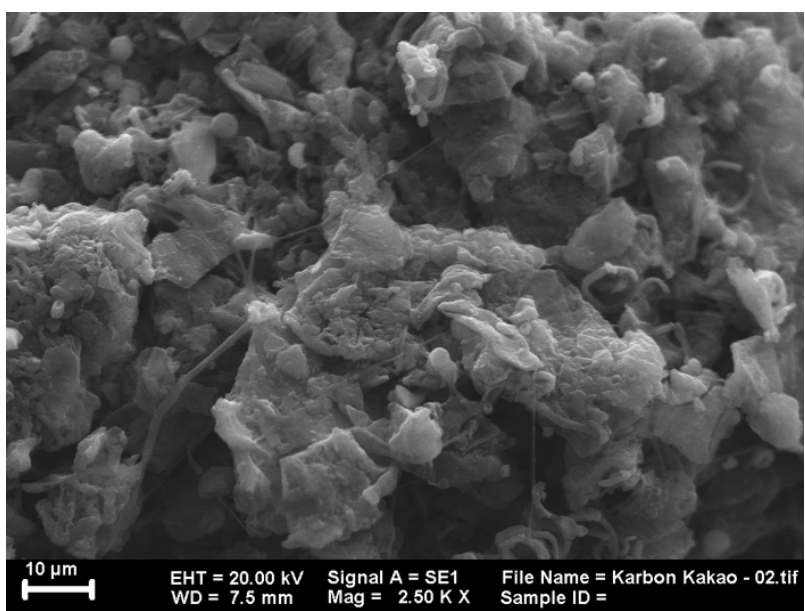

Fig. 2. SEM Result of Activated Charcoal at Carbonized Temperature $300^{\circ} \mathrm{C}$

\subsection{Scanning Electron Microscope}

Scanning electron microscopy (SEM) was employed for characterizing the surface morphology of the charcoals. Fig. 2 shows the SEM micrograph of the activated sample. The surface of the sample is rough and pores are not evenly distributed. This image can be analyzed that the carbonization and $\mathrm{HCl}$ treated only create gradual porosity. Table 1 illustrates the elemental analysis of the activated charcoal. The major component is carbon with some oxygen. The carbon majority is in agreement with the XRD results [20], while the existence of oxygen is in agreement with the FTIR analysis for the presence of cellulose, hemicellulose, and lignin.

\subsection{Characterization of Biodiesel}

The use of activated charcoal in the pretreatment of waste cooking oil influenced the characterization of the biodiesel. The characterization result shows in Table 2. which the values correspond to the Indonesian National Standard requirement.

The free fatty acid value should not be more than $1 \%$ because it may lead to the soap formation and hence lower the yield [21]. Improper handling of oil would cause it to oxidize in the presence of water to free fatty acid due to hydrolysis and oxidation of the triglycerides. Therefore only the charcoal activated at $300^{\circ} \mathrm{C}$ is suitable. 
Table 2. Properties of Biodiesel Purified Using Activated Charcoal.

\begin{tabular}{|c|c|c|c|c|}
\hline \multirow{2}{*}{ Property } & \multicolumn{3}{|c|}{$\begin{array}{c}\text { Activated charcoal at } \\
\text { carbonized temperatures }\end{array}$} & $\begin{array}{c}\text { Indonesian } \\
\text { National } \\
\text { Standard }\end{array}$ \\
\cline { 2 - 4 } & $250^{\circ} \mathrm{C}$ & $300^{\circ} \mathrm{C}$ & $350^{\circ} \mathrm{C}$ & \\
\hline $\begin{array}{c}\text { Density } \\
\mathrm{kg} / \mathrm{m}^{3}\end{array}$ & 869.5 & 872.5 & 865.5 & $850-890$ \\
\hline $\begin{array}{c}\mathrm{KV} @ 2 / 40 \mathrm{C} \\
\mathrm{mm} / \mathrm{sec}\end{array}$ & 4.177 & 4.149 & 3.916 & $2.3-6.0$ \\
\hline$\% \mathrm{FFA}$ & 1.28 & 0.43 & 1.024 & \\
\hline $\mathrm{FP}\left({ }^{\circ} \mathrm{C}\right)$ & 190 & 175 & 180 & Min. 100 \\
\hline $\mathrm{CP}\left({ }^{\circ} \mathrm{C}\right)$ & 10.9 & 8.3 & 9 & Max. 18 \\
\hline $\mathrm{PF}\left({ }^{\circ} \mathrm{C}\right)$ & 17 & 13 & 14.1 & Max. 28 \\
\hline
\end{tabular}

\section{Conclusion}

The use of cocoa pod activated charcoal at $300^{\circ} \mathrm{C}$ in the pretreatment of waste cooking oil was shown to be successful in lowering the free fatty acid and able to meet the Indonesian National Standard requirement.

The authors would like to thank Directorate General of Higher Education Ministry of Research, Technology and Higher Education for the funding of this research through the Student Creativity 2016 Republic of Indonesia.

\section{References}

1. M.S. Kocak, E. Ileri, Z. Utlu, Experimental study of emission parameters of biodiesel fuels obtained from canola, hazelnut, and waste cooking oils, Energy Fuels, 21, 3622-3626 (2007)

2. M. Ahmad, M.A. Khan, M. Zafar, S. Sultana, Practical Handbook on Biodiesel Production and Properties, CRC Press, Boca Raton FL USA (2013)

3. R.S. Putra, T.S. Juliantoa, P. Hartono, R.D. Puspitasaria, A. Kurniawan, Pretreatment of UsedCooking Oil as Feed Stocks of Biodiesel Production by Using Activated Carbon and Clay Minerals, International Journal of Renewable Energy Development, 3(1), 33-35 (2014)

4. C. Theivarasu, S. Mylsamy, Equilibrium and Kinetic adsorption studies of Rhodamine-B from aqueous solutions using cocoa (Theobroma cacao) shell as a new adsorbent, IJEST, 2, 6284-6292 (2010)

5. O. Bello, M. Ahmad, T. Siang, Utilization of Cocoa Pod Husk for the removal of Remazol Black B reactive dye from aqueous solutions: kinetic, equilibrium and thermodynamic studies, Trends in Appl Sci Research, 6, 794-812 (2011)
6. F. Ahmad, W. Daud, M. Ahmad, R. Radzi, Using cocoa (Theobroma cacao) shell-based activated carbon to remove 4-nitrophenol from aqueous solution: Kinetics and equilibrium studies, Chem. Eng. Journal, 178, 461- 467 (2011)

7. A. Ahmadpour, The preparation of activated carbon from macadamia nutshell by chemical activation, Carbon, 35, 1723-1732 (1997)

8. F. Adekola, H. Adegoke, Adsorption of blue-dye on activated carbons produced from rice husk, coconut shell and coconut coirpith, Ife J. Sci., 7, 151-157 (2005)

9. A. Jameel, A. Hussain, Removal of heavy metals from wastewater using activated rice husk carbon as adsorbent, Indian J. Environ. Protect, 29, 263-265 (2009)

10. N. Khan, M. Faizal, I. Abustan, M. Azmier, Effect of preparation conditions of activated carbon prepared from rice husk by $\mathrm{ZnCl}_{2}$ activation for removal of $\mathrm{Cu}$ (II) from aqueous solution, Int. J. Eng. Tech., 10, 2731 (2010)

11. K. Ramakrishnan, C. Namasivayam, Development and characteristics of activated carbons from jatropha husk, an agro industrial solid waste, by chemical activation methods, J. Environ. Eng. Manag., 19, 173-178 (2009)

12. R. Malarvizhi, N, Sulochana, Sorption isotherm and kinetic studies of methylene blue uptake onto activated carbon prepared from wood apple shell, J. Environ. Protect Sci., 2, 40-46 (2008)

13. T.A. Bal'burova, V.G. Shiretorova, E.V. Zoltoev, G.I. Khanturgaeva, Production of activated carbons from Pine Nutshells, Russ. J. Appl. Chem., 81, 162164 (2008)

14. C.L. Aik, J. Qipeng, Adsorption of phenol by oilpalm-shell activated carbons, Adsorption, 13, 129137 (2007)

15. S.Y. Gueu, A.G. Adouby, Heavy metals removal in aqueous solution by activated carbon prepared from coconut shell and seed shell of the palm tree, J. Appl. Sci., 6, 2789-2793 (2006)

16. K. Kadirvelu, M. Kavipriya, C. Karthika, N. Vennilamani, S. Pattabhi, Mercury (II) adsorption by activated carbon made from sago waste, Carbon, $\mathbf{4 2 ,}$ 745-752 (2004)

17. I.A. Rahman, B. Saad, Utilisation of Guava seeds as a source of activated carbon for removal of Methylene blue from aqueous solution, Malay. J. Chem., 5, 8-14 (2003) 
18. J. Hayashi, T. Horikawa, I. Takeda, K. Muroyama, F. NasirAni, Preparing activated carbon from various nutshells by chemical activation with $\mathrm{K}_{2} \mathrm{CO}_{3}$, Carbon, 40, 2381-2386 (2002)

19. C. Moreno, F. Carrasco, M.V. Lopez, M.A. Alvarez, Chemical and physical activation of olive-mill waste water to produce activated carbons, Carbon, 39, 1415-1420 (2001)

20. D. Rachmat, A.D. Agustin, D.D. Risanti, Cocoa (Theobroma cacao) pod-based activated carbon by acid activation, $2^{\text {nd }}$ International Seminar on Science and Technology (submitted) (2016)

21. Y.C. Sharma, B. Singh, S.N. Upadhyay, Advancements in development and characterization of biodiesel: a review, Fuel, 87, 2355-2373 (2008)

22. K. S. Chuna, S. Husseinsyaha, H. Osmana, Development of Biocomposites from Cocoa Pod Husk and Polypropylene: Effect of Filler Content and 3-Aminopropyltriethoxylsilane, Polymers from Renewable Resources, Vol. 5, No. 4: 139-156 (2014) 